\title{
DESEMPENHO DE HÍBRIDOS EXPERIMENTAIS E COMERCIAIS DE MILHO PARA PRODUÇÃO DE MILHO VERDE
}

\author{
Performance of experimental and commercial hybrids of maize for the \\ production of green maize
}

\author{
Carlos Juliano Brant Albuquerque ${ }^{1}$, Renzo Garcia Von Pinho' ${ }^{2}$ Iran Dias Borges ${ }^{3}$, \\ Alano Xavier de Souza Filho ${ }^{4}$, Ivan Vilela Andrade Fiorini ${ }^{5}$
}

\begin{abstract}
RESUMO
Conduziu-se este trabalho com objetivo de avaliar o desempenho de 32 híbridos experimentais e 4 híbridos comerciais para produção de milho verde em Lavras, MG. O delineamento utilizado foi de blocos ao acaso com duas repetições. Foram avaliadas sete características de interesse agronômico e comercial para a produção de milho verde. Os dados obtidos foram submetidos à análise de variância, decompondo o efeito dos híbridos em híbridos comerciais, híbridos experimentais e híbridos comerciais versus híbridos experimentais. Foram feitos ainda estudos de correlação entre as diferentes características agronômicas dos híbridos. Entre os híbridos avaliados há híbridos experimentais promissores com desempenho superior a híbridos comerciais amplamente utilizados no Brasil. Considerando as características avaliadas, os híbridos AG 1051, AG 4051, GNS 03, GNS 21, GNS 23 e GNS 35 foram os mais promissores. É possível reduzir o número de características avaliadas em experimentos com milho verde, uma vez que existem associações entre as principais características avaliadas para essa finalidade. A produtividade de espigas empalhadas e despalhadas e a cor dos grãos são características imprescindíveis nessa avaliação.
\end{abstract}

Termos para indexação: Zea mays, milho verde, milho híbrido, características de plantas e espiga.

\section{ABSTRACT}

The objective of this research was to evaluate the performance of thirty-two experimental hybrids and four commercial hybrids of green maize at Lavras, MG. The experimental design was a randomized blocks with two replications. Seven characteristics of agronomic and commercial interest for the production of green maize had been evaluated. For each experiment, the data obtained were submitted to the analysis of variance decomposing the effect of the hybrids in commercial hybrids versus experimental hybrids. There were still made studies of correlation among the different characteristics. Among all of evaluated hybrids, there are experimental promising hybrids with performance superior to the commercial hybrids widely utilized in Brazil. Taking into account all the characteristics evaluated, hybrids AG 1051, AG 4051, GNS 03, GNS 21, GNS 23 and GNS 35 were the most promising. It is possible to reduce the number of characteristics evaluated as green maize, since there are high associations among the main characteristics evaluated for this purpose. The yield of strawed ears along and the color of the grains are indispensable characteristics in that evaluation.

Index terms: Zea mays, green maize, specialty corn, hybrid maize, characteristics plant and ears.

(Recebido em 9 de março de 2006 e aprovado em 24 de janeiro de 2007)

\section{INTRODUÇÃo}

A comercialização do milho verde "in natura" é cada vez mais comum no estado de Minas Gerais. $\mathrm{O}$ volume comercializado nesse estado cresceu $14 \%$ no período de 1999 a 2004 (AGRIDATA, 2005). O mercado de milho verde é composto basicamente por dois segmentos. O primeiro segmento, representado pela Central de Abastecimento de Minas Gerais (CEASA/MG), onde foram comercializadas no ano de 2004, aproximadamente $11.731 .350 \mathrm{~kg}$ de espigas empalhadas das quais mais de $95 \%$ são originadas do próprio estado, tendo valor médio de $\mathrm{R} \$ 0,29$ o quilo (AGRIDATA, 2005). O segundo segmento é o mercado de venda direta aos consumidores finais através de supermercados, feiras livres, "casas de pamonha" e quitandas, sem a intermediação do mercado atacadista.

O milho verde é cultivado de forma intensiva praticamente o ano todo e os maiores preços são obtidos

\footnotetext{
${ }^{1}$ Engenheiro Agrônomo, Doutorando - Empresa de Pesquisa Agropecuária de Minas Gerais/EPAMIG - Cx. P. 12 - 39525-000 - Nova Porteirinha, MG carlosjuliano@epamig.br

${ }^{2}$ Engenheiro Agrônomo, Doutor, Professor Associado - Departamento de Agricultura/DAG - Universidade Federal de Lavras/UFLA - Cx. P. 3037 37200-000-renzo@ufla.br

${ }^{3}$ Engenheiro Agrônomo, Doutor, Professor - Departamento de Ciências Agrárias - Universidade Estadual de Montes Claros/UNIMONTES - Cx. P. 91 39440-000 - Montes Claros, MG - iran.borges@unimontes.br

${ }^{4}$ Engenheiro Agrônomo, Mestre - UNIAGRO - Avenida Belo Horizonte, 140 - João Paulo II - 37550-000 - Pouso Alegre, MG - alanofilho@hotmail.com ${ }^{5}$ Engenheiro Agrônomo, Departamento de Agricultura/DAG - Universidade Federal de Lavras/UFLA - Cx. P. 3037 - 37200-000 - ivanvaf@yahoo.com.br
} 
fora da época normalmente recomendada para o cultivo do milho para grão. Na região Sul de Minas Gerais, com exceção dos meses de abril a julho, em que, normalmente, as temperaturas são baixas, as condições climáticas permitem a semeadura do milho no decorrer do ano, desde que sejam satisfeitas as exigências hídricas da cultura por meio de irrigações suplementares nos períodos de déficit hídrico (PAIVA JUNIOR, 1999).

No Sul de Minas Gerais, o cultivo é realizado principalmente por pequenos produtores que, na maioria das vezes, utilizam para essa finalidade cultivares que nem sempre satisfazem às exigências do mercado consumidor. Avaliando 200 cultivares de milho disponíveis no mercado de sementes do Brasil no ano 2000, apenas 13 foram recomendadas pelas empresas para a produção de milho verde, entretanto com uso não exclusivo para essa finalidade (ARAÚJO et al., 2000).

Para atender tanto aos interesses da indústria de envasamento quanto à produção para o consumo "in natura" e ao próprio produtor, o milho verde deve apresentar alguns atributos para melhor aceitação, como, por exemplo, possibilidade de plantio durante o ano todo, produtividade a campo acima de $12 \mathrm{t} \mathrm{ha}^{-1}$, ciclo variando entre 90 e 110 dias, longevidade no período da colheita, bom empalhamento e rendimento industrial de grãos igual ou maior que $30 \%$ (PEREIRA FILHO et al., 2003). Também deve-se considerar espigas maiores que $15 \mathrm{~cm}$ de comprimento e $3 \mathrm{~cm}$ de diâmetro além dos grãos das espigas de coloração creme e amarelo claro, como atributos indispensáveis para comercialização.

Considerando o tempo de conservação, as cultivares que produzem espigas com menores perdas de qualidade comercial após a colheita são preferidas por proporcionarem aumento no período de comercialização (PAIVA JUNIOR, 1999).

Em supermercados, a comercialização é feita em bandejas de material biodegradável, onde se acondicionam de quatro a cinco espigas semidespalhadas, envoltas por um filme de PVC transparente (EMBRAPA, 2003). A embalagem influi no processo metabólico das espigas, no que se refere a entrada de oxigênio, importante para a respiração aeróbica do produto, permitindo, assim, trocas gasosas. Estudos realizados com embalagens de filme PVC esticável e filme plástico PD-941 relataram menores perdas de teores de amido quando em condições de refrigeração e, conseqüentemente, melhor conservação do produto para comercialização (MARCOS et al., 1999). Em algumas situações, quando comercializado a granel, o milho suporta, no máximo, dois dias sem perder a qualidade e as características exigidas pelo mercado consumidor (FERNANDES \& OLIVEIRA, 1985).

Alguns produtores integram as atividades de pecuária e agricultura, aproveitando, na forma de silagem, as plantas do milho e o restante das espigas não comercializáveis que ficam na área. Quando se pretende utilizar os restos culturais como sub produto do milho verde para alimentação de bovinos, deve-se optar por cultivares que produzam mais massa, em geral plantas mais altas e mais tardias (PARENTONI et al., 1990).

Em virtude do elevado custo das sementes e grande necessidade de utilização das mesmas para maior eficiência da atividade agrícola é de grande importância a identificação de cultivares apropriadas para produção de milho verde, em uma determinada região. Sendo assim, o presente trabalho objetivou avaliar o desempenho de 32 híbridos experimentais e 4 híbridos comerciais para produção de milho verde, em Lavras/MG.

\section{MATERIAL E MÉTODOS}

Foram utilizados 36 híbridos de milho, sendo 32 híbridos simples experimentais, provenientes do programa de melhoramento da empresa Geneseeds Recursos Genéticos em Milho Ltda, e quatro híbridos comerciais, recomendados por empresas produtoras de sementes para a produção de milho verde (Tabela 1).

Conduziu-se o experimento no ano agrícola 2004/05, na área experimental do Departamento de Agricultura da Universidade Federal de Lavras (UFLA). O resultado das análises químicas e físicas do solo da área experimental indicou um teor de 55 dag $\mathrm{Kg}^{-1}$ de argila, 4,0 dag $\mathrm{Kg}^{-1}$ de matéria orgânica, de $11,5 \mathrm{mg} \mathrm{dm}^{-3}$ de fósforo, de $67 \mathrm{mg} \mathrm{dm}^{-3}$ de potássio, de 5,8 de $\mathrm{pH}$ em $\mathrm{H}_{2} \mathrm{O}$ e de $65,6 \%$ de saturação de bases.

O município de Lavras está situado na região Sul do Estado de Minas Gerais, a $21^{\circ} 14$, de latitude sul e $45^{\circ} 00$ de longitude oeste, com uma altitude de 920 m (BRASIL, 1992). O clima da região é do tipo mesotérmico de inverno seco (Cwb). A temperatura média é de $22,1^{\circ} \mathrm{C}$ no mês mais quente e de $15,8^{\circ} \mathrm{C}$ no mês mais frio, sendo a média anual de $19,4^{\circ} \mathrm{C}$. A pluviosidade média anual é de $1.530 \mathrm{~mm}$, com evaporação total no ano de $1.034,3 \mathrm{~mm}$ e umidade relativa anual de 76,2\% (BRASIL, 1992).

O preparo do solo foi realizado de maneira convencional com uma aração e duas gradagens. A semeadura foi realizada manualmente no dia 30/10/2004 utilizando-se oito sementes por metro linear. $\mathrm{O}$ desbaste foi realizado manualmente quando as plantas apresentavam com três a quatro folhas, deixando-se a densidade de 50.000 plantas ha ${ }^{-1}$.

$\mathrm{O}$ delineamento experimental utilizado foi em blocos casualizados, com duas repetições. As parcelas foram constituídas de quatro fileiras de $5 \mathrm{~m}$, com espaçamento de $0,8 \mathrm{~m}$ entre fileiras, sendo as duas centrais consideradas como úteis para efeito de coleta de dados e observações. 
Tabela 1 -Características dos híbridos comerciais e experimentais avaliados na safra 2004/05. UFLA, Lavras, MG, 2008.

\begin{tabular}{|c|c|c|c|}
\hline Híbridos & Base genética & Empresa & Ciclo \\
\hline GNZ 2004 & Híbrido simples & Geneze & Precoce \\
\hline AG 4051 & Híbrido triplo & Agroceres & Normal \\
\hline AG 1051 & Híbrido duplo & Agroceres & Normal \\
\hline 2 C 577 & Híbrido simples & Dow AgroSciences & Precoce \\
\hline GNS 02 & Híbrido simples & Geneseeds & Normal \\
\hline GNS 03 & Híbrido simples & Geneseeds & Normal \\
\hline GNS 04 & Híbrido simples & Geneseeds & Normal \\
\hline GNS 05 & Híbrido simples & Geneseeds & Normal \\
\hline GNS 06 & Híbrido simples & Geneseeds & Normal \\
\hline GNS 07 & Híbrido simples & Geneseeds & Normal \\
\hline GNS 08 & Híbrido simples & Geneseeds & Normal \\
\hline GNS 09 & Híbrido simples & Geneseeds & Normal \\
\hline GNS 11 & Híbrido simples & Geneseeds & Precoce \\
\hline GNS 13 & Híbrido simples & Geneseeds & Precoce \\
\hline GNS 14 & Híbrido simples & Geneseeds & Precoce \\
\hline GNS 16 & Híbrido simples & Geneseeds & Precoce \\
\hline GNS 19 & Híbrido simples & Geneseeds & Normal \\
\hline GNS 20 & Híbrido simples & Geneseeds & Normal \\
\hline GNS 21 & Híbrido simples & Geneseeds & Precoce \\
\hline GNS 22 & Híbrido simples & Geneseeds & Normal \\
\hline GNS 23 & Híbrido simples & Geneseeds & Precoce \\
\hline GNS 24 & Híbrido simples & Geneseeds & Normal \\
\hline GNS 26 & Híbrido simples & Geneseeds & Normal \\
\hline GNS 27 & Híbrido simples & Geneseeds & Precoce \\
\hline GNS 28 & Híbrido simples & Geneseeds & Normal \\
\hline GNS 29 & Híbrido simples & Geneseeds & Precoce \\
\hline GNS 32 & Híbrido simples & Geneseeds & Precoce \\
\hline GNS 33 & Híbrido simples & Geneseeds & Precoce \\
\hline GNS 34 & Híbrido simples & Geneseeds & Normal \\
\hline GNS 35 & Híbrido simples & Geneseeds & Normal \\
\hline GNS 37 & Híbrido simples & Geneseeds & Precoce \\
\hline GNS 38 & Híbrido simples & Geneseeds & Precoce \\
\hline GNS 39 & Híbrido simples & Geneseeds & Normal \\
\hline GNS 41 & Híbrido simples & Geneseeds & Normal \\
\hline GNS 42 & Híbrido simples & Geneseeds & Normal \\
\hline GNS 44 & Híbrido simples & Geneseeds & Normal \\
\hline
\end{tabular}


O controle de plantas daninhas foi realizado com o uso do herbicida Primestra Gold na dosagem de 3,0 1 ha $^{-1}$, na pré-emergência das plantas, logo após a semeadura. Quando necessário, realizaram-se capinas manuais com enxada deixando as parcelas totalmente livres de plantas daninhas e também aplicação de inseticidas para o controle da lagarta do cartucho (Spodoptera frugiperda). As adubações de plantio foram efetuadas com $400 \mathrm{~kg} \mathrm{ha}^{-1} \mathrm{do}$ formulado $08-28-16+0,5 \%$ de $\mathrm{Zn}$ e as coberturas foram realizadas com $300 \mathrm{~kg} \mathrm{ha}^{-1}$ do formulado $30-00-20$, quando as plantas apresentavam-se com cinco a seis folhas totalmente expandidas.

Foram avaliadas as características de produtividade de espigas empalhadas (PEE), (peso total das espigas da área útil de cada parcela em $\mathrm{Kg} \mathrm{ha}^{-1}$ ), produtividade de espigas comerciais despalhadas (PEC), (peso das espigas maiores que $15 \mathrm{~cm}$ e com diâmetro superior a $3 \mathrm{~cm} \mathrm{em} \mathrm{Kg} \mathrm{ha}^{-1}$ ), porcentagem de espigas comerciais (\%EC), (razão entre o peso de espigas comerciais e o peso total de espigas da parcela), altura de plantas (AP), (medida de seis plantas representativas de cada parcela), tempo de comercialização das espigas despalhadas colocadas em badeja de isopor, seladas com plástico e mantidas em ambiente à sombra (PVC), (determinado pelo numero de dias que as espigas não foram mais comercializadas por alteração na cor, textura ou aroma), tempo de comercialização das espigas empalhadas (PALHA) mantidas em ambiente à sombra (número de dias que as espigas não são mais comercializadas devido enrugamento dos grãos) e coloração dos grãos (COR), seguindo escala estabelecida a priori, variando de 1 a 5 , em que 1 correspondia à cor creme dos grãos; 2 a cor amarelo-claro; 3 a cor amarela; 4 a cor amarelo-escuro e 5 alaranjada.

Os dados obtidos foram submetidos à análise de variância decompondo-se o efeito das cultivares em cultivares comerciais, cultivares experimentais e cultivares comerciais versus cultivares experimentais. As médias foram agrupadas considerando separadamente os grupos de cultivares comerciais e cultivares experimentais. As médias foram agrupadas pelo teste de Scott-Knott, a 5\% de probabilidade, utilizando o programa estatístico GENES (CRUZ, 1997).

Foram feitos ainda estudos de correlação de Pearson entre as diferentes características agronômicas dos híbridos.

\section{RESULTADOS E DISCUSSÃO}

As médias das características avaliadas dos grupos de híbridos comerciais e experimentais, assim como o coeficiente de variação $(\mathrm{CV})$, o erro padrão da média (EPM) e a significância dos efeitos de suas respectivas análises de variância, estão apresentadas na tabela 2 .

Foi observada diferença significativa entre os dois grupos de híbridos para produtividade de espigas empalhadas (PEE), produtividade de espigas comerciais (PEC), porcentagem de espigas comerciais (\%) e altura de

Tabela 2 - Coeficiente de variação (CV), erro padrão da média (EPM), níveis de significância e valores médios de híbridos e grupos de híbridos comerciais e híbridos experimentais para produtividade de espigas empalhadas (PEE), produtividade de espigas comerciais despalhadas (PEC), porcentagem de espigas comerciais (\%EC), altura de plantas (AP), tempo de comercialização de espigas despalhadas e acondicionadas nas bandejas de isopor com plástico (PVC), tempo de comercialização de espigas empalhadas (PALHA) e cor dos grãos (COR) em Lavras, MG. UFLA, Lavras, MG, 2008.

\begin{tabular}{lrrrrrrrr}
\hline & \multicolumn{4}{c}{ Médias } & & & \multicolumn{3}{c}{ Níveis de significância $^{1}$} \\
\cline { 2 - 3 } \cline { 8 - 9 } Variáveis & Hib. Com. & Hib. Exp. & Híbridos & C.V. & EPM & Hib. Com. & Hib. Exp. & H.C. vs H.E. \\
\hline PEE & 21292,69 & 18412,52 & 19852,61 & 8,98 & 1189,57 & 0,0004 & 0,0002 & 0,0001 \\
PEC & 12394,54 & 8746,97 & 10588,44 & 11,20 & 714,60 & 0,0050 & 0,0062 & 0,0001 \\
\%EC & 90,63 & 78,54 & 84,59 & 12,74 & 7,19 & 0,0620 & 0,0060 & 0,0032 \\
AP & 2,54 & 2,28 & 2,41 & 6,38 & 0,10 & 0,6400 & 0,0380 & 0,0001 \\
PVC & 4,38 & 4,69 & 4,54 & 17,23 & 0,57 & 0,0007 & 0,0009 & 0,3056 \\
PALHA & 3,13 & 2,55 & 2,84 & 32,22 & 0,59 & 0,1273 & 0,3300 & 0,0754 \\
COR & 2,75 & 2,48 & 2,62 & 31,81 & 0,57 & 0,0491 & 0,0077 & 0,3817 \\
\hline
\end{tabular}

${ }^{1}$ Níveis de significância - Probabilidade dos efeitos de híbridos comerciais (Hib.com), híbridos experimentais (Hib. Exp.) e do efeito de híbridos comerciais versus híbridos experimentais (H.C. vs H.E.). 
plantas (AP) (Tabela 2). Nesse caso, o grupo de híbridos comerciais teve maior valor.

Dentre os híbridos comerciais, verificou-se que os híbridos AG 4051 e AG 1051 apresentaram maiores produtividades para PEE (Tabela 3). Já entre os híbridos experimentais, 16 mostraram-se com melhor desempenho para PEE. Entre os grupos de híbridos experimentais houve diferença significativa entre os híbridos para PEE, sendo que alguns híbridos experimentais apresentaram valores próximos de PEE aos obtidos pelos híbridos comerciais. Exemplo disso ocorreu com o híbrido experimental GNS 35, que apresentou valores médios de PEE mais altos que a maioria dos híbridos comerciais avaliados.

É desejável, para a produção do milho verde maior peso de espigas comerciais (PEC), pois estas são as espigas que realmente serão comercializadas. Deve-se ressaltar que o consumidor dá preferência a espigas de maior diâmetro e maior comprimento. Espigas mais finas e menores geralmente são rejeitadas, permanecendo por um período de tempo prolongado nos estabelecimentos comerciais, o que favorece a sua deterioração.

Dentre os híbridos comerciais, verificou-se que os híbridos AG 4051, AG 1051 e 2C577 apresentaram maior PEC (Tabela 3). Em trabalho de avaliação de 13 cultivares de milho verde na região de Lavras, Paiva Junior (1999) relatou produtividades médias inferiores às obtidas no presente trabalho para as cultivares AG 4051 e AG 1051. $\mathrm{Na}$ densidade de 55 mil plantas $\mathrm{ha}^{-1}$ foram observadas produtividades médias de espigas comerciais de $9.480 \mathrm{~kg}$ ha ${ }^{1}$ para o híbrido AG 4051 e $8.540 \mathrm{~kg} \mathrm{ha}^{-1}$ para o AG 1051.

Dentre os híbridos experimentais, houve diferença significativa para a PEC, sendo que a PEC para os híbridos de melhor desempenho variou de $9865 \mathrm{~kg} \mathrm{ha}^{-1}$ (GNS 21) a $13881 \mathrm{~kg} \mathrm{ha}^{-1}$ (GNS 20).

É comum a comercialização de milho verde em espigas. Nesse caso, a maior porcentagem de espigas comerciais por hectare é de fundamental importância.

Considerando a porcentagem de espigas comerciais (\%EC), não foram observadas diferenças significativas entre os híbridos comerciais. Já entre os híbridos experimentais, foram observados 24 híbridos com maior $\%$ EC. Entre os dois grupos, os híbridos comerciais apresentaram maiores \%EC.

Na produção de milho verde em áreas irrigadas é comum o estabelecimento de contratos de cooperação com indústrias que fazem o enlatamento do milho. Essas indústrias seguem um cronograma rígido de recebimento da matériaprima, o que exige uso intensivo da área cultivada onde são realizados diversos plantios consecutivos. Nessa situação é comum dar-se preferência por cultivares precoces e de porte reduzido, de tal forma que a incorporação dos restos culturais não prejudique o plantio posterior, possibilitando um maior número de colheitas por ano e por local (BORDALLO et al., 2005). Entretanto, quando se pretende utilizar os restos culturais na alimentação de bovinos, devese optar por cultivares que produzam mais massa e que, em geral, possuem plantas mais altas e mais tardias (PARENTONI et al., 1990).

Não foram verificadas diferenças significativas entre os híbridos comerciais para altura de plantas. Entre os híbridos experimentais, 20 apresentaram maior altura de plantas (Tabela 3). Os sete híbridos experimentais de maior produtividade de espigas comerciais apresentaram também maiores alturas de plantas.

A comercialização do milho verde em supermercados é feita, principalmente, em espigas despalhadas, embaladas em bandejas com filme plástico de PVC, enquanto que nas feiras livres a comercialização é por meio de espigas empalhadas. Desse modo, é importante que as cultivares tenham maior tempo de comercialização, considerando as duas formas de comercialização.

Foi constatada diferença significativa entre os híbridos comerciais e experimentais apenas no tempo de comercialização, em bandejas com filme plástico de PVC (PVC) (Tabela 2). Resultados semelhantes foram observados por Evensen \& Boyer, citados por Braz (2002), segundo os quais os tempos de conservação nas embalagens de PVC também foram afetados pela cultivar.

Considerada a embalagem em bandeja de isopor, destacaram-se os híbridos comerciais AG 4051 e AG 1051. Apesar de não se observar diferenças entre os dois grupos para essa característica (Tabela 2), alguns híbridos experimentais apresentaram valores médios superiores que os híbridos comerciais. Quando foram acondicionadas em embalagens de isopor com filme plástico (PVC), alguns híbridos não apresentaram espigas com enrugamento dos grãos como critério de descarte, mas tiveram alterações na cor dos grãos, bem como forte odor, possivelmente devido à fermentação.

Considerando o tempo de comercialização na palha (PALHA), não foram constatadas diferenças entre os híbridos comerciais e entre os experimentais. O período de conservação das espigas empalhadas nessas condições variou de 2 dias a 3,5 dias (Tabela 3); nesse período verificou-se enrugamento dos grãos como critério de descarte das espigas. Resultados semelhantes foram obtidos por Henz et al. (1999) que, avaliando a conservação pós-colheita de espigas de milho verde, observaram tempo de comercialização das espigas empalhadas variando de 3 a 4 dias, quando as mesmas foram mantidas em temperatura ambiente. 
Tabela 3 - Valores médios de produtividade de espigas empalhadas (PEE), produtividade de espigas comerciais (PEC), porcentagem de espigas comerciais (EC), altura de plantas (AP), tempo de comercialização de espigas despalhadas nas bandejas (PVC), tempo de comercialização de espigas empalhadas (PALHA) e coloração dos grãos (COR) para 36 cultivares de milho verde avaliadas em Lavras, MG. UFLA, Lavras, MG, 2008.

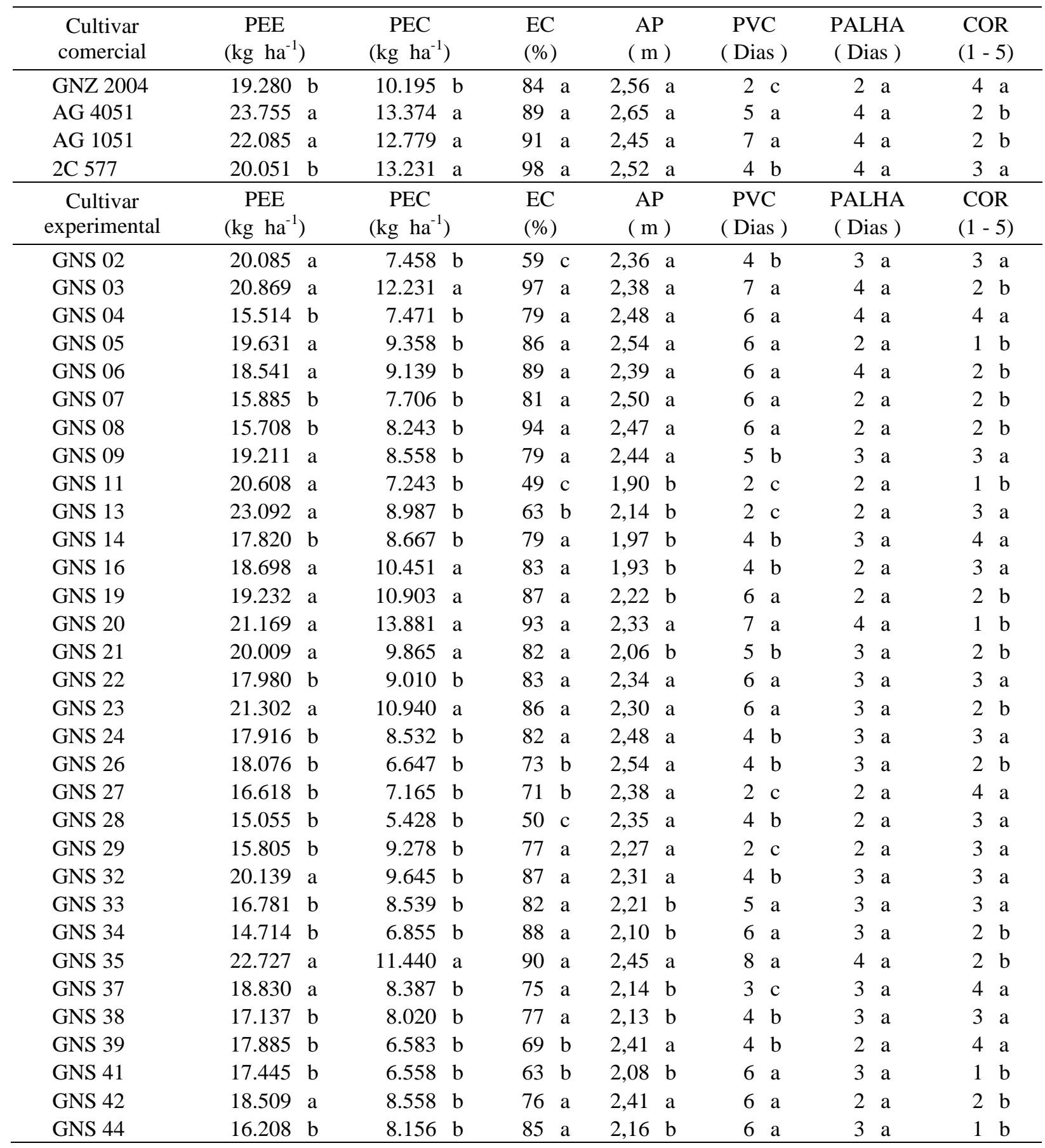

Médias seguidas pela mesma letra na coluna entre os híbridos comerciais e entre os híbridos experimentais não diferem entre si, pelo teste de Scott e Knott, a 5\% de probabilidade. 
A aparência do produto destinado à alimentação humana é de fundamental importância para a sua comercialização. A cor dos grãos do milho verde exerce grande influência na aceitação pelo consumidor. De acordo com Pereira Filho et al. (2003), as espigas com grãos de coloração mais clara são preferidas quando o produto é destinado ao consumo de milho verde in natura.

Constatou-se que, entre os híbridos comerciais, o AG1051 e o AG4051 apresentaram as melhores colorações para o comércio de milho verde in natura. Os híbridos experimentais de coloração adequada para o comércio do milho verde (notas 1 e 2), melhor desempenho de produtividade, maior porcentagem de espigas comerciais, além da maior altura das plantas, foram os híbridos GNS 03, GNS 20, GNS23 e GNS35 (Tabela 3).

Com a análise de correlação linear, pode-se decidir pela redução do número de características avaliadas em experimentos futuros com milho verde, uma vez observada grande dependência entre uma variável e outra. A relação entre duas variáveis é perfeita quando o valor de $\mathrm{r}$ for igual a -1 (o aumento de uma característica implica a diminuição da outra) ou +1 (o aumento de uma característica implica o aumento da outra).

Foram constatadas correlações positivas e altamente significativas, como, por exemplo, entre o PEE com o PEC (Tabela 4). Resultados semelhantes foram obtidos por Oliveira et al. (1987) e Paiva Junior (1999) que, na avaliação de cultivares comerciais para a produção de milho verde, observou correlações positivas e altamente significativas entre o peso de espigas empalhadas e o peso de espigas comerciais.

A avaliação da PEE $\left(\mathrm{kg} \mathrm{ha}^{-1}\right)$ seria suficiente para inferir sobre os resultados de PEC, uma vez que ocorreu correlação alta e significativa entre essas duas características.

A cor dos grãos apresentou correlação negativa e significativa com o maior tempo de comercialização na embalagem de isopor com filme plástico.

Observou-se correlação significativa entre a altura de planta com a porcentagem de espigas comerciais. Bordallo et al. (2005) avaliaram, por meio de correlação, o grau de associação de caracteres agronômicos visando à produção de milho verde e concluíram que também houve correlação positiva entre a altura de plantas e o peso médio e o comprimento médio das espigas, indicando que a seleção para plantas altas implicará em espigas maiores e mais pesadas.

Nos ensaios iniciais para avaliação de híbridos para a produção de milho verde, geralmente é avaliado um grande número de características. As correlações positivas entre o PEE com o PEC permitem a redução do número de características a serem avaliadas, pois não seria necessário despalhar as espigas e avaliar o diâmetro e o comprimento daquelas com padrão comercial. Assim, as cultivares com maior produtividade de espigas empalhadas e de coloração creme ou amarelo-claro poderia ser o principal critério de avaliação de cultivares, para a produção de milho verde.

Tabela 4 - Correlações de Pearson envolvendo o peso de espigas empalhadas (PEE), peso de espigas comerciais (PEC), porcentagem de espigas comerciais (EC), altura de plantas (AP), tempo de comercialização nas embalagens de isopor com filme plástico (PVC), tempo de comercialização na própria palha (PALHA) e cor dos grãos (COR) considerando os 36 híbridos. UFLA, Lavras, MG, 2008.

\begin{tabular}{lcccccc}
\hline Características & PEC & EC & AP & PVC & PALHA & COR \\
\hline PEE & $0,70^{* *}$ & $0,19^{\mathrm{ns}}$ & $0,12^{\mathrm{ns}}$ & $0,09^{\mathrm{ns}}$ & $0,44^{* *}$ & $-0,21^{\mathrm{ns}}$ \\
PEC & & $0,71^{* *}$ & $0,24^{\mathrm{ns}}$ & $0,33^{*}$ & $0,58^{* *}$ & $-0,21^{\mathrm{ns}}$ \\
EC & & & $0,35^{*}$ & $0,55^{* *}$ & $0,48^{* *}$ & $-0,16^{\mathrm{ns}}$ \\
AP & & & & $0,23^{\mathrm{ns}}$ & $0,28^{\mathrm{ns}}$ & $0,05^{\mathrm{ns}}$ \\
PVC & & & & $0,52^{* *}$ & $-0,56^{* *}$ \\
PALHA & & & & & & \\
\hline
\end{tabular}

* : significativo, a $5 \%$ de probabilidade, pelo teste $\mathrm{t}$.

** : significativo, a $1 \%$ de probabilidade pelo teste $\mathrm{t}$.

ns : Não significativo 


\section{CONCLUSÕES}

Dentre os híbridos avaliados há híbridos experimentais promissores com desempenho superior a híbridos comerciais, amplamente utilizados no Brasil para a produção de milho verde.

Os híbridos AG 1051 AG 4051, GNS 03, GNS 23 e GNS 35 foram os mais promissores para a produção de milho verde.

É possível reduzir o número de características avaliadas em experimentos com milho verde, uma vez que existem associações entre as principais características avaliadas para essa finalidade. A produtividade de espigas empalhadas e despalhadas e a cor dos grãos são características imprescindíveis nessa avaliação.

\section{REFERÊNCIAS BIBLIOGRÁFICAS}

AGRIDATA. Sistema de informações do agribusiness de Minas Gerais. Belo Horizonte: Secretaria de Estado de Agricultura Pecuária e Abastecimento, 2005. Disponível em: <http://agridata.mg.gov.br>. Acesso em: 22 ago. 2005.

ARAÚJO, P. C.; PERIN, A.; MACHADO, A. T.; ALMEIDA, D. L. Avaliação de diferentes variedades de milho para o estádio de "verde" em sistemas orgânicos de produção. In: CONGRESSO NASCIONAL DE MILHO E SORGO: A INOVAÇÃO TECNOLÓGICA E A COMPETITIVIDADE NO CONTEXTO DOS MERCADOS GLOBALIZADOS, 23., 2000, Uberlândia, MG. Resumos... Uberlândia: UFU, 2000.

BORDALLO, P. N.; PEREIRA, M. G.; AMARAL JÚNIOR, A. T.; GABRIEL, A. P. C. Análise dialélica de genótipos de milho doce e comum para caracteres agronômicos e proteína total. Horticultura Brasileira, Brasília, v. 23, n. 1, p. 123-127, jan./mar. 2005.

BRAZ, R. F. Conservação pós-colheita de espigas de milho verde em função do cultivar, da temperatura e da forma de acondicionamento. 2002. 51 f. Dissertação (Mestrado) - Universidade Federal de Viçosa, Viçosa, 2002 .
BRASIL. Ministério da Agricultura e Reforma Agrária. Normais climatológicas: 1961-1990. Brasília, DF, 1992. 84 p.

CRUZ, C. D. Programa genes: aplicativo computacional em genética e estatística. Viçosa: UFV, 1997. 442 p.

EMPRESA BRASILEIRA DE PESQUISA AGROPECUÁRIA. O cultivo do milho verde. Brasília, DF, 2003.

FERNANDES, J. C.; OLIVEIRA, L. A. A. Aspectos do mercado atacadista do milho verde na Ceasa-RJ. Niterói: PESAGRO-RIO, 1985. 4 p. (Comunicado técnico, 147).

HENZ, G. P.; NOOSA, G. B. de A.; MENDONÇA, N. D. Conservação pós-colheita de espigas de milho verde cv. AG519. Horticultura Brasileira, Brasília, v. 20, n. 200/201, p. 34-140, 1999. Suplemento.

MARCOS, S. K.; HONORIO, L.; JORGES, J. T.; AVELAR, J. A. Influência do resfriamento e do ambiente de armazenamento e da embalagem sobre o comportamento pós-colheita do milho verde. Revista Brasileira de Engenharia Agrícola e Ambiental, Campina Grande, v. 3, n. 1, p. 41-44, 1999.

OLIVEIRA, L. A. A. de; GROSZMAN, A.; COSTA, R. A. da. Caracteres da espiga de cultivares de milho no estádio verde. Pesquisa Agropecuária Brasileira, Brasília, v. 22, n. 6, p. 587-592, jun. 1987.

PAIVA JUNIOR, M. C. Desempenho de cultivares para produção de milho verde em diferentes épocas e densidades de semeadura. 1999. 66 p. Dissertação (Mestrado) Universidade Federal de Lavras, Lavras, 1999.

PARENTONI, S. N.; GAMA, E. E. G.; MAGNAVACA, R.; REIFSCHNEIDER, F. J. B.; BOAS, G. L. V. Milho doce.Informe Agropecuário, Belo Horizonte, v. 14, n. 165, p. 17-22, 1990.

PEREIRA FILHO, I. A.; CRUZ, J. C.; GAMA, E. E. G. Cultivares para o consumo verde. In: EMPRESA BRASILEIRA DE PESQUISA AGROPECUÁRIA. $O$ cultivo do milho verde. Brasília, DF, 2003. p. 17-30. 